\title{
Decision-Makers' Forum On A Unified Strategy For Nuclear Energy
}

November 2004

Idaho National Engineering and Environmental Laboratory Bechtel BWXT Idaho, LLC 


\section{Decision-Makers' Forum}

on a Unified Strategy for
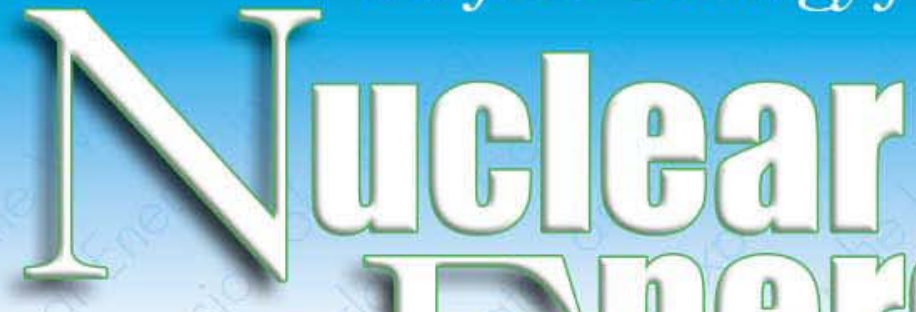

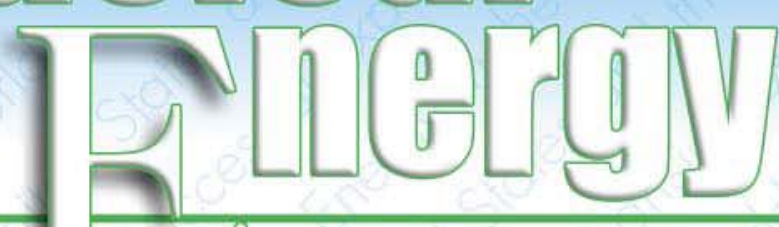
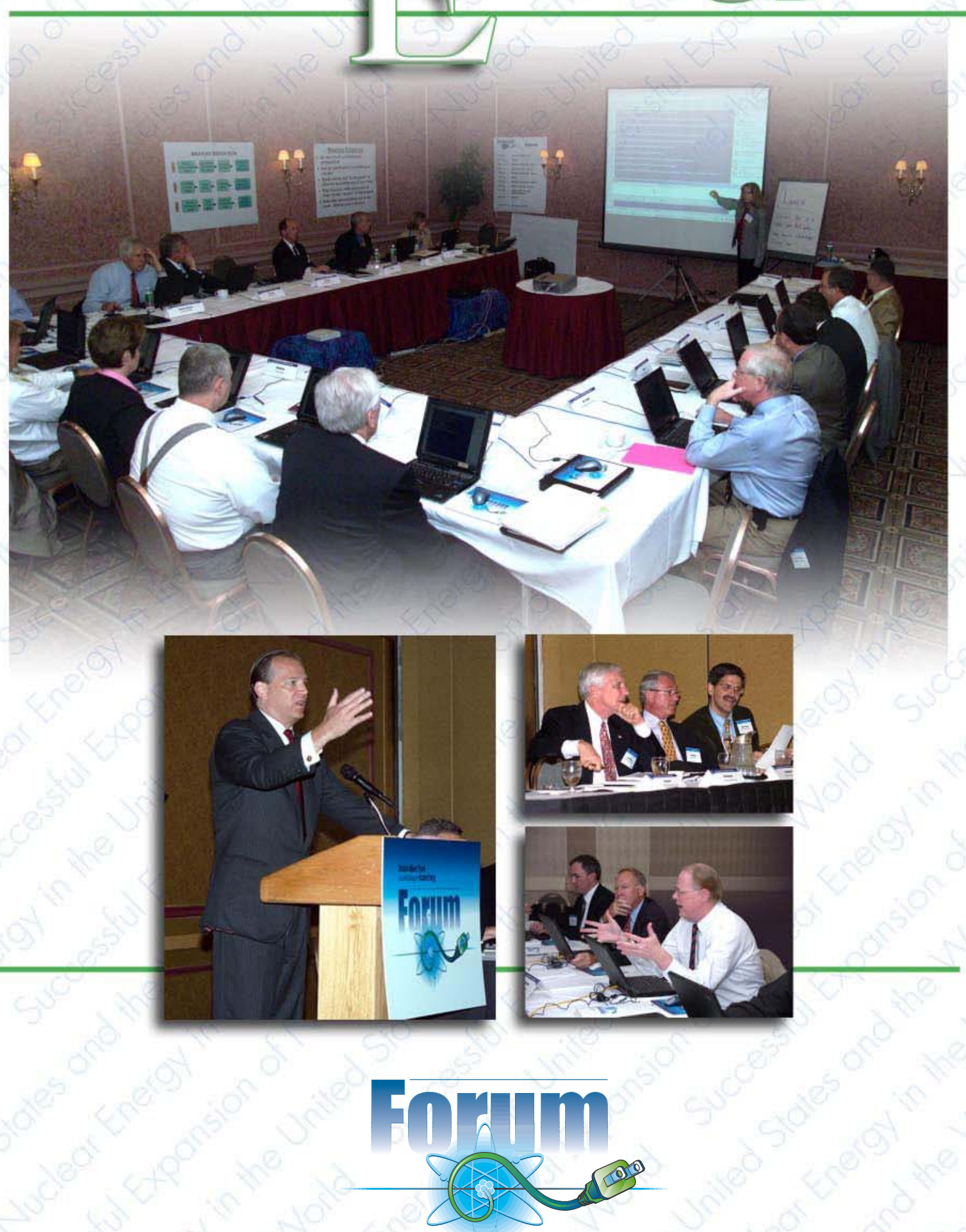


\section{Decision-Makers' Report: A Unified Strategy for Nuclear Energy}

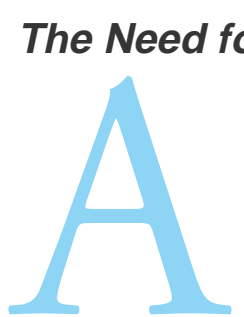

$n$ abundant and secure energy supply is critical to our country's prosperity, and energy supply is now a central issue in global stability and security. Unfortunately, the Unites States continues to steadily increase the fraction of energy it imports from foreign sources. In May 2001, the National Energy Policy noted that this imbalance, "if allowed to continue, will inevitably undermine our economy, our standard of living, and our national security." In addition to these serious impacts, growing concern about air pollution and atmospheric carbon levels hold the potential for global climate change. According to the National Academy of Sciences, the Earth's surface temperature has risen by about 1 degree Fahrenheit in the past century, with accelerated warming during the past two decades. The current energy supply situation clearly demands coordinated action.

Nuclear energy is preeminent in its ability to deliver affordable energy today and meet the growing imperatives for clean air and energy supplies in the future.

A number of sectors within the nuclear energy infrastructure, including the government, industry, national laboratories, and universities have begun to take action. Government and industry, sensing renewed interest in nuclear energy, took steps toward stimulating new plant orders. Government and academia, faced with troubling trends in the vitality of the nuclear science and engineering institutions, took steps to stabilize the nuclear research infrastructure. Finally, government and national laboratories, understanding the global long-term outlook and the prospects for new technology, took steps to establish programs that could deliver new nuclear energy systems and reestablish U.S. leadership in nuclear energy development and deployment around the world.

These sectors developed roadmaps and strategies, but they were not fully integrated. In the spring of 2004, the Department of Energy challenged seven national laboratory directors to create a unified strategy.

\section{The Decision-Makers' Forum}

The laboratories responded by assembling a forum of key decision-makers from the nuclear sectors-prominent leaders who could begin to forge a unified strategy. The Decision-Makers' Forum, held in the summer of 2004, used a format that quickly oriented the participants, began interactions on key themes, and captured input with impartiality and speed. The day-long event produced this report, which presents the unified strategy organized into eight major themes, or imperatives. Each imperative contributes to answer the following question:

\section{To advance nuclear energy in the United States through mid-century, what must happen?}

Each imperative briefly describes a strategic step needed to achieve the common vision of successful expansion of nuclear energy in the United States and the world, and begins to determine the priorities for coordinated action by all sectors. The full set sounds a cogent call for unified action. 


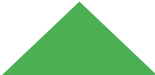 \\ Imperative 1}

\section{We Must Ensure U.S. Energy Security with Bipartisan Initiatives and an Executive Branch Priority on Nuclear Energy}

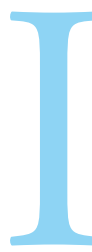

$\mathrm{t}$ is widely accepted that the availability of abundant and secure energy is paramount in determining quality of life and economic prosperity. The National Energy Policy underscores this important reality. Although the policy was followed by a comprehensive energy bill to direct the actions needed to implement the policy, three years of debate and partisan politics have produced no significant progress in addressing energy security for the United States and no significant energy legislation. Our dependence on foreign sources of oil and natural gas continues to grow, placing a high cost on the nation to protect those sources. Meanwhile, owing to parochial and competitive interests, our national investments in domestic energy sources continue to be fragmented and unbalanced.

The Forum participants consistently statedas their highest priority-the need for government leadership in establishing a comprehensive energy policy and supporting legislation. A national initiative on energy security, led by the Administration with strong bipartisan support from Congress, is essential to establish the national resolve and budget priorities needed to achieve success. The comprehensive energy policy and legislation must include the following features:

- A clear vision for achieving energy security through a broad portfolio of domestic energy sources, including nuclear

- An equitable package of incentives for energy production using sources that do not emit greenhouse gases
- Multiyear research and development budgets for advanced energy production technologies in proportion to their ability to meet energy needs through mid-century and beyond.

U.S. leadership in nuclear energy affords considerable benefits to our national security, economic competitiveness, and the global environment. Broad, bipartisan Congressional support and an Administration priority for nuclear energy are essential to achieving these benefits. While a few Forum members believed that the future of nuclear energy could be determined entirely in the market place, the overwhelming consensus of the Forum was that government must take the lead, with support and participation from industry, the research community, and the public.

The Forum recommends several overarching objectives for the national leadership:

- The importance of the Department of Energy's civilian energy mission should be commensurate with its national security mission

- Research and development budgets in nuclear energy must be increased to those of other energy sources and maintained in the future

- The United States should expand collaborations with other world leaders in nuclear energy, notably France, Japan, Russia, and China. 


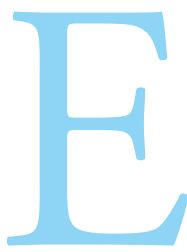

xisting and future U.S. nuclear energy infrastructure requires financial protection from extremely low probability but high consequence events. Price-Anderson legislation provides this protection, and its renewal for a long and predictable term is essential for a viable domestic nuclear industry to raise capital in the financial markets. This protection must include existing reactors and those planned for the future.

The Atomic Energy Act of 1954 provided essential guarantees to the early nuclear industry that catastrophic consequences of unforeseen events would not threaten the existence of companies willing to invest in what was at the time only a partially proven technology. The assurances provided by this legislation have demonstrated their value through the development of nuclear power as a key component of the nation's energy mix. The Price-Anderson Amendments Act of 1988 extended these protections through 2007.

Much has changed since the original legislation. The technology of second-generation reactors has proven robust. Thousands of reactor years of operating experience have resulted in improved management, greater safety, and capacity factors significantly higher than any other large-scale electricity source. Unfortunately, society has seen a less desirable trend toward high-stakes litigation and a sense that decisions of almost any type or impact can be handled by the judicial system.

The guarantees of reason supplied by PriceAnderson are especially necessary if we are to see a continuing renaissance of nuclear power in the United States that includes the construction of new generation reactors. The technical, financial, and social uncertainties of investing in nextgeneration power plants can be reduced appreciably if Congress acts to renew Price-Anderson.

Therefore, the Forum strongly urges Congress to renew Price-Anderson and consider making the provisions of the legislation permanent. 


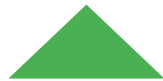 \\ Imperative 3}

\section{We Must Reassert Criteria, Achieve Licensing, and Begin Operation of Yucca Mountain}

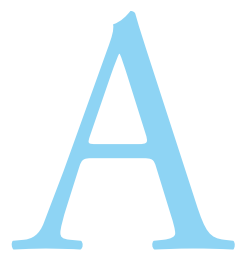

sustainable and viable nuclear power industry in the United States requires a long-term approach for the disposition of high-level waste. On-site pool storage of spent fuel, although safe and secure, is a short-term approach to the backend of the nuclear fuel-cycle. The opening of the first commercial high-level waste repository is a highly visible milestone and important to achieve public confidence that a long-term solution to disposing of high-level waste is at hand.

The Forum believes that implementation of the Nuclear Waste Policy Act must move forward in a technically responsible manner to achieve this objective at Yucca Mountain. In 2001, the Department of Energy, after 20 years of R\&D to characterize the site, recommended Yucca Mountain as a suitable site for burial of spent fuel and high-level waste. Subsequently, the President and Congress approved the recommendation, and the Department of Energy is now working on the submission of a license application to the Nuclear Regulatory Commission (NRC).

The Forum recommends three actions to continue to move the repository forward, along with a fourth action to begin the consolidation of stored spent fuel:

First, seek Federal action that reasserts or redefines achievable repository performance criteria. In July 2004, the U.S. Court of Appeals ruled that the 10,000-year compliance period was not sufficient. Two possible approaches could be considered: One is to argue that a 10,000 year compliance period is consistent with the Environmental Protection Agency's (EPA's) management of risks from long-lived hazardous nonradioactive materials and codify it with Congressional action. The alternative approach is to recognize that the EPA must identify acceptable long-term repository performance and argue that, given societal uncertainties, the allowable dose to the public should not exceed natural background radiation and that this bounds any dramatic change in performance.

Second, continue efforts to obtain a construction permit for Yucca Mountain. This year, the Yucca Mountain project has a potential budget shortfall of $\$ 700$ million at a crucial time when it is preparing to submit the license application to the NRC. The Forum strongly supports continued and stable funding of the project to obtain a combined construction/ operating license from the NRC.

Third, plan for the operation of the Yucca Mountain repository and associated technical issues. Given acceptable EPA criteria and continuing NRC licensing activities, associated technical issues that relate to the operation of the Yucca Mountain repository must be addressed. One issue that needs to be addressed is the safe and secure transportation of spent fuel to the site and the development of the associated infrastructure. Another issue that needs to be addressed is the proper planning and design of the aboveground operations.

While licensing, construction, and operation of a first repository at Yucca Mountain is achievable, it has a lengthy time horizon. Thus, the Forum also recommends a fourth action that, rather than continue to add interim storage at individual reactor sites, the government proceed with authorization and development of regional or centralized interim storage, using proven and safe technologies. This action would meet the government's responsibility to the utilities to take ownership of the spent fuel while reducing storage costs and security concerns at the plant sites. 


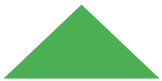 \\ Imperative 4}

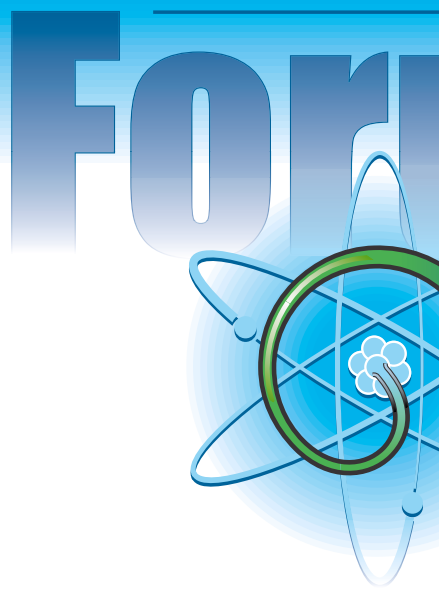

\section{We Must Deploy Generation III Reactors}

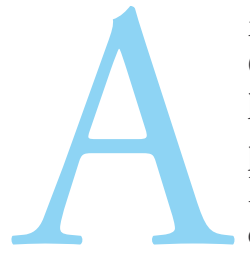

number of recent and promising Generation III reactor designs have obtained, or are in the process of obtaining, Nuclear Regulatory Commission design certification. To be a principal contributor in the balanced national energy mix of mid-century, these designs need to be deployed by industry in concert with the NP 2010 program. Market entry will likely require the formation of consortia of utility and supplier organizations with some level of government financial guarantees to provide an environment conducive to securing the necessary capital. Financial market support will be driven by plant cost (capital and operating) and schedule and related risks. Improvements in these areas are required for near-term deployment. In the future, industry must also continue to improve the technology during deployment with the goal of achieving $\mathrm{N}^{\text {th }}$-of-a-kind economics and minimizing the volume of high-level waste. For long-term prosperity, the industry must evaluate opportunities and build the domestic nuclear supply chain as a successful competitor in the future global marketplace.

Government has historically been instrumental in developing capital-intensive programs and infrastructure. Recent examples include production incentives for solar, wind, and biomass energy systems and government loan guarantees for natural gas pipelines. If nuclear power is to achieve the role envisioned in the National Energy Policy, it needs and deserves equal treatment.

The 25-year hiatus in new nuclear power plant orders presents a significant psychological barrier for new orders: The history of regulatory uncertainty and uncontrolled construction costs and schedules create a perceived risk for owners when they evaluate investment in new nuclear plants. However, these uncertainties will be minimized once the first few new plants are operating - a comprehensive approach that enables the first new nuclear plants will open the door for many more. The financial barriers to new construction, particularly the costs for the first reactors, must be addressed and overcome. The Forum recommends government assistance to cover the one-time licensing and engineering costs to bring Generation III reactors on line. These incentives are short-term actions needed to revitalize the industry now.

Another important disincentive to new plant construction is the current depreciation schedule for capital facilities. In today's corporate atmosphere where the emphasis is on quarterly earnings, the impact of several years of construction costs before revenues begin is very challenging. The Forum recommends a change in depreciation methods to allow more of the capital costs to be depreciated as they are incurred. The nuclear construction industry must also step up to the challenge by minimizing construction durations. Plant standardization, factory-built modular components, and new construction methods should be exploited to reduce the time from groundbreaking to completion to less than four years. 


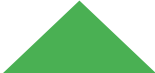 \\ Imperative 5}

\section{We Must Demonstrate Predictable and Efficient Nuclear Plant Licensing Processes}

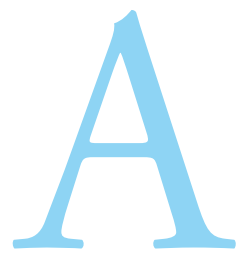

11 aspects of nuclear plant licensing need to be predictable and efficient, and include riskbased analysis. Demonstration of the early site permitting process is now in progress, and industry and government need to quickly advance it to a predictable and efficient process. Combined construction and operating licensing will be the next major challenge. For the future, NRC must begin now to develop the staffing and infrastructure that can effectively support the development of licensing and regulation for new Generation IV designs.

The chief regulatory concern of Forum participants is the lack of predictability. While the Forum believes that continued safety is paramount to industry expansion, safety review must also be efficient. The large capital expenditures necessary for nuclear plant construction require extra diligence in minimizing associated finance charges. Regulatory uncertainty increases the potential for operating delays, while also increasing the risk premium added to standard interest rates.

The government has initiated a number of regulatory process improvements designed to bring key issues to the review process at an early stage. These commendable steps move much of the potential for regulatory delay to the time period before major construction expenditures. Government and industry need to work more closely together to proof test these new processes and overcome bureaucratic inertia. The process for license extension and power uprates of currently operating plants appears to be working well, but improvements in the duration of reviews are needed. For example, the Forum is pleased with the regulatory adoption of the early site permitting process, but is concerned that the government allowed processing delays to affect the third permit application.

The Forum also encourages the successful demonstration of the combined construction and operating license process, especially with regard to provisions that require timely application of intervener appeals. With earlier consideration of key issues in licensing, there also needs to be early consideration of intervener comments, objections, and any subsequent appeals. This approach will put focus on intervener issues within the review process. 


\section{. \\ Imperative 6}

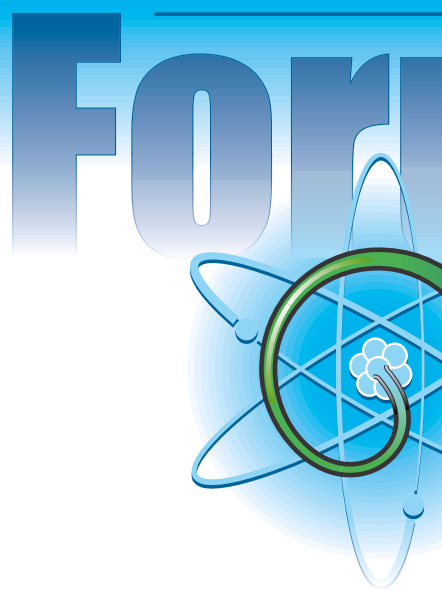

\section{We Must Develop and Deploy Generation IV Reactors and Advanced Fuel Cycles}

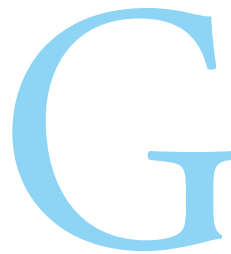

enerations III and IV systems are complementary and must share an integrated strategy for their development. Generation III will 'answer the mail' of interest in new construction by overcoming barriers, meeting near-term needs for new and replacement electric capacity, and building public confidence in nuclear energy. Generation IV will 'build a sustainable future' with new energy sources such as hydrogen and advanced fuel cycles for long-term sustainability, which can be built and operated — safely and securely—in many regions around the world. Both Generations III and IV will share technology development as they develop and mature. Both generations must be successful since together they achieve a necessary set of objectives that enable nuclear energy to be a highly valued long-term energy source.

The major near-term challenge for Generation IV in the United States is successful development of a Next Generation Nuclear Plant to demonstrate economical hydrogen production and highefficiency electricity generation. To be ready for commercial deployment in about two decades, many technical challenges must be met in nuclear fuel qualification, materials, reactor design and construction, and hydrogen production technology. Strong support from industry will be central to its success, bringing market savvy and the motivation to achieve NRC licensing. Thus far, government has focused Generation IV on a few, most promising systems. Government must now make this a flagship program that attracts and focuses the relevant industries, along with the best and brightest talent from the R\&D community, to ensure its successful development and deployment.

In the mid- and long-term, Generation IV must meet the challenges arising from the widescale deployment of nuclear energy in the United States. This involves first developing advanced fuel cycle technologies to enable repository optimization, and then developing technologies that can greatly reduce the need for future repositories implied by an increasing nuclear market share. To the first objective, government and the R\&D community should explore technologies for high burnup fuels, and spent fuel treatment, partitioning, and transmutation technologies that can be deployed before mid-century. To the second objective, the government and $\mathrm{R} \& \mathrm{D}$ community should undertake long-term development of a closed fuel cycle system that can make major advances toward the Generation IV goals of economics, safety, sustainability, and proliferation resistance and physical protection. This will require development and demonstration of a fast reactor that delivers solid performance toward the Generation IV goals and best fits within an optimal and sustainable closed fuel cycle for the United States.

Generation IV programs open up a key opportunity for increasing U.S. leadership in the international community that is developing and deploying advanced reactors and fuel cycles. A robust Generation IV program offers considerable benefit to our global nuclear security by helping to guide choices, improve standards and knowledge, and develop preferred technologies that will resolve issues in nuclear nonproliferation and improve global materials management. 


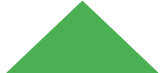 \\ Imperative 7}

\section{We Must Reestablish a Vibrant Educational Infrastructure}

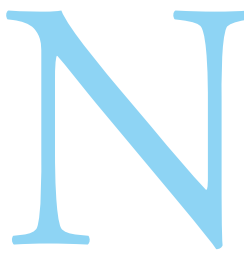

uclear engineering programs and departments were formed in the late 1950s and 1960 s from interdisciplinary efforts in many of the top research universities, providing the manpower for this new technical discipline, with an initial emphasis in fission reactor engineering. In the same time period, university nuclear reactors were constructed and began their operation for many of these programs, providing key facilities needed for research and training of students engaged in this profession. Since the 1960s, U.S. universities have led the world in this technology with a commitment to furnish the necessary human resources and the associated infrastructure.

Recently, the demand for nuclear-trained personnel is again on the rise. The demand for new staff at operating U.S. nuclear power plants is increasing and will undoubtedly remain high, given the plans for plant-life extension of most light-water reactors in the United States. In addition, there is continued growth of nuclear power in the Pacific Rim using primarily U.S.developed technology, and renewed DOE and industry activity promises continued advances in the design of future nuclear reactors and advanced nuclear fuel cycles.

The Forum believes that a key objective should be to enhance the human resources needed to develop innovations in nuclear science and engineering as well as to maintain a vibrant human resource for the continuance of the discipline through the $21^{\text {st }}$ century. This effort should not only focus on nuclear science and engineering, but also be expected to involve allied disciplines (chemical, electrical, and mechanical engineering, materials science, and others) to develop an interdisciplinary thrust for future human resource development. In addition, the Forum recognizes the need for appropriately trained technicians in reactor operations and industrial health physics as essential to providing key support to nuclear energy.

The DOE Office of Nuclear Energy, Science and Technology is committed to and is providing on-going support for enhancing the future nuclear science and engineering human resource. The national laboratories must also join this missionpartnering with university programs through longterm projects, or providing key nuclear infrastructure and resources. The Forum recommends the following federal support:

- Expand the support of the unique research infrastructure facilities that exist at universities in nuclear engineering

- Expand on-going support for university research programs, including research grants targeted for junior faculty

- Continue support for undergraduate scholarships via the industry-DOE matching grants program, and expand the graduate fellowship program to Masters traineeships and a larger pool of Doctoral fellowships.

- As new plants are ordered, expand training programs for specialty crafts and technicians to prepare the skilled workforce necessary for construction and operation. 


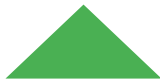 \\ Imperative 8}

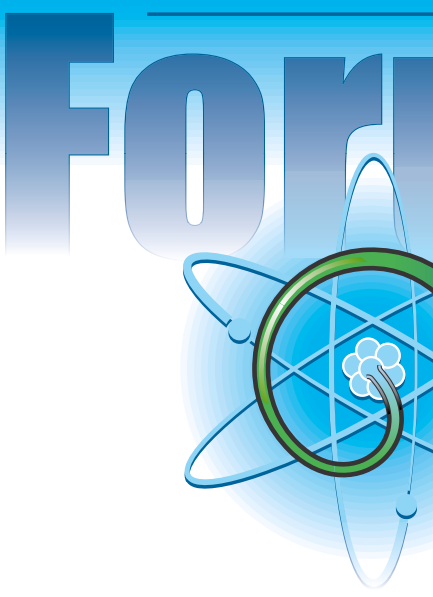

We Must Build Public Confidence and Support for Nuclear Energy

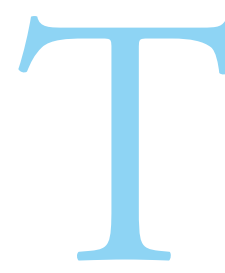

he combination of electricity shortages, higher gasoline and natural gas prices, and conflict and continuing tension in the Middle

East are attracting critical attention from the public on the issues of energy security and sustainability. The nuclear community has the opportunity to proactively make the case for nuclear with increased and effective communications: The dialog must emphasize the benefits of nuclear energy with respect to the environment, safety, sustainability, energy prices, and energy independence. The nuclear community must focus on educating policy makers and educators, and reaching a larger portion of the public. Overall, the communications must persuasively establish the vital role of nuclear in the current energy mix, and the need for an expanding role in the future.

Public support for nuclear energy is high among people who live close to operating nuclear plants or receive a major portion of their electricity from them. This portion of the public most closely affected by nuclear energy is also best able to judge the actual safety, consistent availability, environmental benefits and competitiveness of nuclear energy.

Those who receive their information on nuclear energy from secondary sources have both a lower opinion and less understanding of nuclear issues. A number of groups with political and social agendas have systematically used biased or incorrect information to stigmatize energy generation in general and nuclear energy in particular. The resulting 'political correctness' on energy issues has resulted in numerous poor decisions impacting the nation's energy infrastructure, leading to shortages, outages, and pricing spikes.

Industry, government, academia, and the laboratories need to work in concert to overcome the misinformation the public has received on energy issues, so that policy makers will be free to objectively evaluate the value to society of nuclear power and all other energy sources. Industry and government must inform people on the true cost of all energy sources and the value of maintaining a viable energy mix, while the academic and laboratory sectors must help educate people on the environmental and sustainability aspects of energy generation. All sectors can help the public appreciate the magnitude of energy usage and its relationship to our economy and quality of life.

The result of this outreach will be an informed public - better able to understand the complexities of energy issues and more willing to support the reasoned positions of government and utility officials promoting achievable energy options.

The Forum is confident that nuclear energy will fare well when the public has full and balanced information on energy issues: The public will know that all energy sources have environmental impacts and that nuclear's impacts are comparatively small. The public will know that nuclear energy has an outstanding safety record. Finally, the public will know that nuclear energy can be sustained for many hundreds of years, and that the steady, consistent deployment of nuclear plants brings secure and abundant energy at a stable and affordable price. 


\section{Forum Process and Plenary}

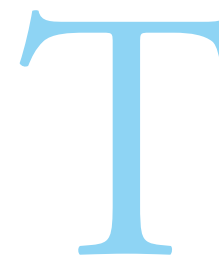

he Forum took place on July 13, 2004 in Washington, D.C. To begin the day, a group of plenary speakers brought perspectives from the government, industrial, academic, and national laboratory sectors.

The Forum was energized by an address from Mr. Kyle E. McSlarrow, Deputy Secretary of Energy. He pointed out that the late 1990s were the bookend of a decade' of decline for nuclear energy with the failure of licensing for Shoreham, nuclear energy $\mathrm{R} \& \mathrm{D}$ funding at zero, and academic nuclear engineering enrollments down by two-thirds. At the same time, the seeds of renewal were already rooted in the vast improvements in plant capacity by industry and the strong endorsement of the President's Council of Advisors on Science and Technology. He asserted that nuclear energy must rise above supplying $20 \%$ of U.S. electricity generation, that it must become a central link to a hydrogen economy, and that it cannot be judged alone because it is already 'woven into the fabric of the future.'

The Forum was guided by the top-level vision of seven national laboratory directors, which was presented to the Forum by Dr. Paul Robinson, Director of Sandia National Laboratories:

The overarching vision is to achieve sustainable peace, prosperity, and environmental quality, enabled through immediate U.S. leadership in the global expansion of nuclear energy systems.

Dr. Robinson emphasized the rapidly increasing global demand for energy and the growing U.S. demand for imported oil and gas. He also summarized the laboratory directors' proposed plan of action to achieve the primary goals of (1) improving air quality and increasing energy security, (2) reducing nuclear waste, and (3) reducing the risk of nuclear proliferation.

Mr. Jim Reinsch, President of Bechtel Nuclear Power and incoming President of the American Nuclear Society, presented the industry perspective.
He emphasized the potential global warming impact of continued burning of fossil fuels and the highly competitive position that nuclear energy now has because of the outstanding performance of the current fleet of nuclear plants. Mr. Reinsch highlighted a number of activities underway by utilities to prepare for the next order of a new nuclear plant and by vendors to offer plants with improved safety and economics. He also presented his view of the primary elements that will effect a new plant order, which includes spent fuel management, regulatory certainty, infrastructure, proven technology, public and bipartisan support, and financial attractiveness.

Dr. Michael Corradini, recent Chair of the Nuclear Engineering Department Heads Organization, presented the university perspective. Despite a two-thirds drop in nuclear engineering undergraduate enrollment between 1990 and 2000, enrollment has now completely rebounded. Although graduate level enrollment numbers are still a concern, these are expected to rebound also. Dr. Corradini emphasized that to ensure an available and well-trained workforce for an expanded nuclear industry, universities will need increased and predictable budgets to support graduate-level students and junior faculty members.

Following the plenary, the participants divided into two breakout groups. Each group brainstormed and discussed the imperatives needed to meet the question, "what must happen?" During the remainder of the day, the groups were facilitated through the formulation and ranking of thirteen strategies, along with ideas about specific actions to support them and important relationships between them. Immediately following the Forum day, a small writing team further consolidated the thirteen ranked strategies into eight imperatives and produced a summary report for comment by all participants. This final report was produced from participant feedback and further review of the original Forum discussion. 


\section{Forum Participants}

Jack B. Allen

Senior Vice President, Nuclear Power

Plants

Westinghouse

Jacques Besnainou

Executive Vice President and

Chief Operating Officer

AREVA-COGEMA

E. Michael Campbell

Vice President, GT-MHR

General Atomics

Michael Corradini

Professor and Department Chair

University of Wisconsin, and Chair

Nuclear Engineering Department Heads

Organization

James Duderstadt

President Emeritus, and Professor

University of Michigan

James Ferland

President and CEO

LES

William Gauntt

Director, Business Development

Washington Group International, Inc.

Eugene S. Grecheck

Vice President, Nuclear Support Services

Dominion Energy, Inc.

Joseph Green

Chief Mechanical Engineer

Stone \& Webster/Shaw Group

William F. Griffith

Vice President, Global Strategy Marketing

Bechtel Power

Frank Hahne

Vice President, Business Development

Nuclear Fuel Services
David J. Hill

Associate Laboratory Director

Oak Ridge National Laboratory

Robert W. Jewell

Vice President, Energy

Dow Hydrocarbons \& Resources, Inc.

Bennett Johnston

President

Johnston \& Associates

W. Proctor Jones

Partner

Johnston \& Associates

Dan Keuter

Vice President

Entergy

James A. Lake

Associate Laboratory Director

Idaho National Engineering and

Environmental Laboratory

John R. Longenecker

President and General Manager

Longenecker \& Associates, Inc.

Marilyn Kray

Vice President, Project Development

Exelon Nuclear

Bill Martin

Washington Policy \& Analysis

Kyle E. McSlarrow

Deputy Secretary of Energy

Department of Energy

Richard A. Meserve

Chair

Carnegie Institute

Dave Modeen

Vice President and Chief Nuclear Officer EPRI
Kenneth L. Peddicord

Professor and Vice Chancellor

Texas A\&M University

H. Peter Planchon

Director, Nuclear Technology Division

Argonne National Laboratory

John Polcyn

President

AECL Technologies, Inc.

James Reinsch

President, Bechtel Nuclear

Bechtel Power

C. Paul Robinson

Laboratory Director

Sandia National Laboratories

Larry Scully

President

Scully Capital Services

Steve Smith

Director, Energy \& Petrochemicals

BASF Corporation

Dave Swindle

Vice President, Business Acquisitions

Kellogg Brown \& Root, Inc.

John Tuck

Policy Advisor

Baker Donelson

Joe Turnage

Senior Vice President

Constellation Energy Group

Peter Wells

Marketing Manager

General Electric Energy 